\title{
The Thermodynamic Evaluation of the Interphase Distribution of Elements in the Chromium and Nickel-containing System
}

\section{Valentina Alekseevna Salina, Oleg Vadimovich Zayakin, and Vladimir Ivanovich Zhuchkov}

Institute of Metallurgy of the Ural Branch of the Russian Academy of Sciences, Yekaterinburg, Russia

\section{Abstract}

The results of thermodynamic modeling of the process of element reducing from a chrome-containing ore-lime melt by silicon ferronickel depending on temperature are presented in this article. The consumption of reducing agent is equal to $105 \%$ of the required stoichiometric amount of reducing agent for complete reduction of iron and chromium in the temperature range of $1300-2200^{\circ} \mathrm{C}$. The chemical composition of the ore-lime melt is, wt. \%: $24 \mathrm{Cr}_{2} \mathrm{O}_{3} ; 13 \mathrm{FeO} ; 42 \mathrm{CaO} ; 3 \mathrm{SiO}_{2} ; 9 \mathrm{MgO} ; 9 \mathrm{Al}_{2} \mathrm{O}_{3}$ and

Corresponding Author: Valentina Alekseevna Salina valentina_salina@mail.ru

Received: 5 February 2019 Accepted: 6 March 2019 Published: 17 March 2019

Publishing services provided by Knowledge E

(c) Valentina Alekseevna Salina et al. This article is distributed under the terms of the Commons Attribution License, which permits unrestricted use and redistribution provided that the original author and source are credited.

Selection and Peer-review under the responsibility of the NIOKR-2018 Conference Committee. of silicon ferronickel is, wt. \%: $65 \mathrm{Si} ; 28 \mathrm{Fe} ; 7 \mathrm{Ni}$. The HSC Chemistry 6.12 software package developed by Outokumpu Research Oy (Finland) is used. The composition of oxide $\mathrm{Cr}_{2} \mathrm{O}_{3}-\mathrm{FeO}-\mathrm{CaO}-\mathrm{SiO}_{2}-\mathrm{MgO}-\mathrm{Al}_{2} \mathrm{O}_{3}$ and metallic $\mathrm{Fe}-\mathrm{Si}-\mathrm{Ni}-\mathrm{Cr}$ systems are calculated using the module «Equilibrium Compositions». A gas phase pressure is $1 \mathrm{~atm}$. The gas phase of the system contains $2,24 \mathrm{~m}^{3} \mathrm{~N}_{2}$. It is established that the increase in the process temperature from 1300 to $2200^{\circ} \mathrm{C}$ contributes to reducing of the degree of chromium reduction from 98,9 to $69,8 \%$. The degree of reduction of aluminum and magnesium increases from 0,2 to $8,7 \%$ and from 0,007 to $2,5 \%$ respectively, and the degree of reduction of iron doesn't change over the entire temperature range and is equal to $100 \%$. The chromium content in the metallic phase decreases with increasing temperature from 51,7 to $41 \%$ and the residual $\mathrm{CrO}$ content in the slag increases. The chemical composition of the alloy is, wt. \%: $50,41 \mathrm{Cr} ; 44,06 \mathrm{Fe} ; 1,97 \mathrm{Si} ; 3,3 \mathrm{Ni}$; 0,035 Mg; $0,21 \mathrm{Al} ; 0,005 \mathrm{P}$ at the temperature of $1700^{\circ} \mathrm{C}$. The results of thermodynamic modeling can be used for laboratory experiments and technological calculations for obtaining chromium and nickel-containing complex ferroalloys suitable for smelting stainless steel grades.

Keywords: thermodynamics, system, interphase distribution, reducing agent consumption, degree of recovery, temperature, chromium, nickel

\section{Introduction}

The development of new technologies or modernization of existing technological processes in metallurgy is based on the results of experiments and thermodynamic model- 
ing (TM). The knowledge of the thermodynamic character of process behavior is necessary to obtain primary data on new processes. The known methods of thermodynamic calculations [1-3] make it possible to quickly and efficiently solve a number of actual and promising problems. We have reviewed the current domestic [4, 5] and foreign [6-9] articles about TM reduction processes for producing chromium-containing alloys. In the articles [10-12] the method of complex processing of domestic oxidized nickel ores was proposed. The product of this method is the silicon ferronickel. There is no information about the interfacial distribution of chromium during silicothermic reduction using silicon ferronickel in the literature.

The purpose of this work is to study the possibility of the silicon using of the silicon ferronickel as a reducing agent for elements of a chrome ore-lime melt. And also the effect of temperature on the interfacial distribution of chromium by thermodynamic modeling was estimate.

\section{Materials and Methods}

To carry out the TM of the process of recovery of elements, the following chemical composition of the ore-lime melt (this composition is close to the composition of industrial melts of low-carbon ferrochrome of the existing technological schemes) is selected, wt. \%: $24 \mathrm{Cr}_{2} \mathrm{O}_{3} ; 13 \mathrm{FeO} ; 42 \mathrm{CaO} ; 3 \mathrm{SiO}_{2} ; 9 \mathrm{MgO} ; 9 \mathrm{Al}_{2} \mathrm{O}_{3}$. The complex ferroalloy containing was used, wt. \%: $65 \mathrm{Si} ; 28 \mathrm{Fe} ; 7 \mathrm{Ni}$.

The HSC Chemistry 6.12 software package developed by Outokumpu Research Oy (Finland) [1] was used. The software is based on the minimization of the Gibbs free energy and the variational principles of thermodynamics. It makes possible to determine the thermodynamic constants of chemical reactions $(\Delta \mathrm{H}, \Delta \mathrm{S}, \Delta \mathrm{G}, \mathrm{K})$ under isobaric and isothermal conditions of the process. The algorithm of the program "GIBBS" for Gibbs potential minimization was used. The calculations were performed in the approximation of the ideal solution.

The composition of the multicomponent oxide $\mathrm{Cr}_{2} \mathrm{O}_{3}-\mathrm{FeO}-\mathrm{CaO}-\mathrm{SiO}_{2}-\mathrm{MgO}-\mathrm{Al}_{2} \mathrm{O}_{3}$ and metallic Fe-Si-Ni-Cr systems was calculated using the Equilibrium Compositions module at the temperature range $1300-2200^{\circ} \mathrm{C}$. The rational consumption of reducing agent was $1.05 \mathrm{~m}_{\text {reduc. agent }}[13]\left(\mathrm{m}_{\text {reduc.agent }}\right.$ is the amount of reducing agent which is stoichiometric necessary for the complete reduction of chromium and iron) and the pressure of the gas phase was $1 \mathrm{~atm}$. The gas phase of the system contained 2,24 $\mathrm{m}^{3} \mathrm{~N}_{2}$ (gas) as a neutral additive to speed up a calculation [14]. The data of bivalent chromium oxide ( $\mathrm{CrO}$ ) was introduced into the HSC Chemistry 6.12 PC database. 


\section{Research Results}

The results of the TM of the recovery process of elements depending on temperature $(t)$ (where a consumption of reducing agent is $1,05 \mathrm{~m}_{\text {reduc.agent }}$ ) are presented in the form of the following graphical dependencies:

1. the change of a degree of recovery of elements (П) (Fig. 1);

2. the change of the equilibrium composition of the metal (Fig. 2);

3. the change of the equilibrium composition of the slag (Fig. 3).

The calculation of the reduction degree of elements as a function of temperature (Fig. 1) showed that the increasing of the process temperature helps to reduce the degree of chromium reduction by $29,4 \%$ (from 98,9 to $69,8 \%$ ). This dependence can be explained how a result of the reaction of chromium reduction by silicon. This reaction is exothermic and proceeds with the release of heat [16]. The obtained dependences of the chromium reduction degree on temperature have good agreement with the results presented in [17]. It should be noted that the highest rate of reduction of chromium is observed in the high-temperature region $\left(1700-2200^{\circ} \mathrm{C}\right)$. The degree of iron reduction doesn't change over the entire temperature range and is equal to $100 \%$, while aluminum and magnesium reduction degree increases from 0,2 to $8,7 \%$ and from 0,007 to $2,5 \%$, respectively.

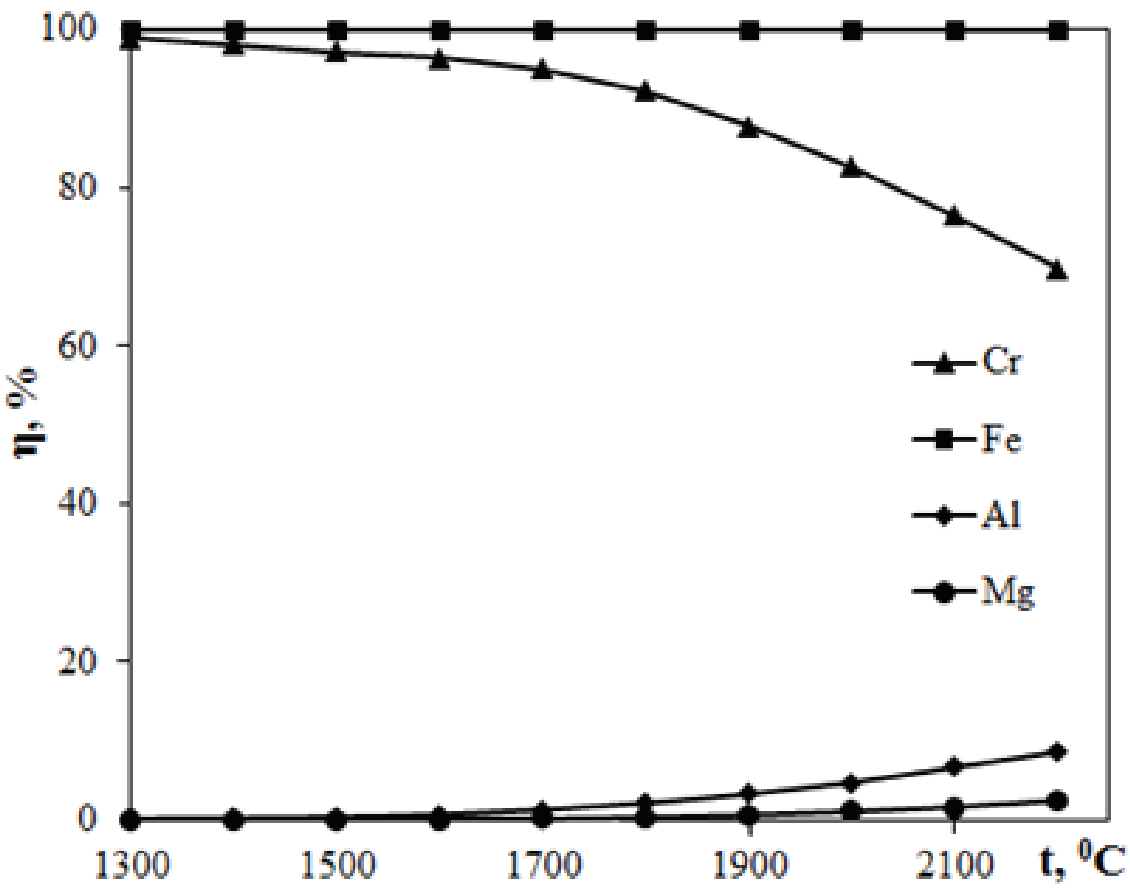

Figure 1: The change of the degree of reduction of elements $(\eta)$ depending on the temperature $(t)$ with the consumption of reducing agent of $1.05 \mathrm{~m}_{\text {reduc.agent }}$. 
Figures 2 and 3 show the interfacial distribution of elements in the metal and slag at the range of temperatures of $1300-2200^{\circ} \mathrm{C}$. The distribution depends on the content of the initial charge materials, the degree of recovery of the elements and the vaporization of elements. An increase of the process temperature contributes to the decrease of the chromium content in the metal from 51,7 to $41 \%$ at the given thermodynamic parameters (Fig. 2). The significant decrease of the chromium content in the metal is observed at the temperature of more than $1700^{\circ} \mathrm{C}$ and reaching the temperature of $2200^{\circ} \mathrm{C}$ the concentration of chromium decreases by $18,7 \%$. At the same time, the $\mathrm{CrO}$ concentration in the slag is proved at a temperature above $1487^{\circ} \mathrm{C}$ in [15]. It increases from temperature of $1700^{\circ} \mathrm{C}$, and reaches $7,5 \%$ at $2200^{\circ} \mathrm{C}$ (Fig. 3).

The iron content in the metal increases in direct proportion to the increase in temperature from 43,4 to $48,7 \%$, which is proved by the decrease of the degree of the extraction of chromium to the metal phase. With increasing temperature, silicon in metal rises from 1,4 to $4,6 \%$ and the content of the element is less than $1,97 \%$ (Fig. 2) at $1700^{\circ} \mathrm{C}$, which corresponds to the required value according to GOST 4757-91 for low carbon ferrochrome. The $\mathrm{SiO}_{2}$ content of the slag decreases with temperature by $12,5 \%$. The decrease is associated with the vaporization of silicon ( $\mathrm{SiO}$ ) into the gas phase and dilution of the oxide phase due to an increase of the chromium oxide content (Fig. 3). The nickel concentration in the metal slightly increases from 3,3 to 3,7\% in the temperature range under consideration, which is caused by a decrease of the degree of chromium transition to the metal phase. The content of magnesium and aluminum in the metal is insignificant and amounts up to $0,04 \%$ and $0,21 \%$ at temperatures of $1700^{\circ} \mathrm{C}$, respectively (Fig. 2), it happens with a decrease in the concentration of their oxides ( $\mathrm{MgO}$ and $\mathrm{Al}_{2} \mathrm{O}_{3}$ ) in the slag in the temperature range under consideration (Fig. 3). The amount of $\mathrm{CaO}$ in the slag decreases by $3,8 \%$ with increasing temperature from 1300 to $2200^{\circ} \mathrm{C}$.

The slag phase composition is represented not only by simple oxides but also by double and ternary compounds: silicates and aluminates of calcium and magnesium. The content of $\mathrm{CaO}, \mathrm{SiO}_{2}, \mathrm{MgO}, \mathrm{CrO}$ and $\mathrm{Al}_{2} \mathrm{O}_{3}$ increases with the increasing temperature.

Thus, the TM method has been used to estimate the effect of temperature on the interfacial distribution of chromium during silicothermic reduction of elements from a chromium-containing ore-lime melt by the silicon of the silicon ferronickel. The obtained results can be used for laboratory experiments and technological calculations for obtaining chromium and nickel-containing complex ferroalloys that are suitable for the smelting of stainless steel grades. 


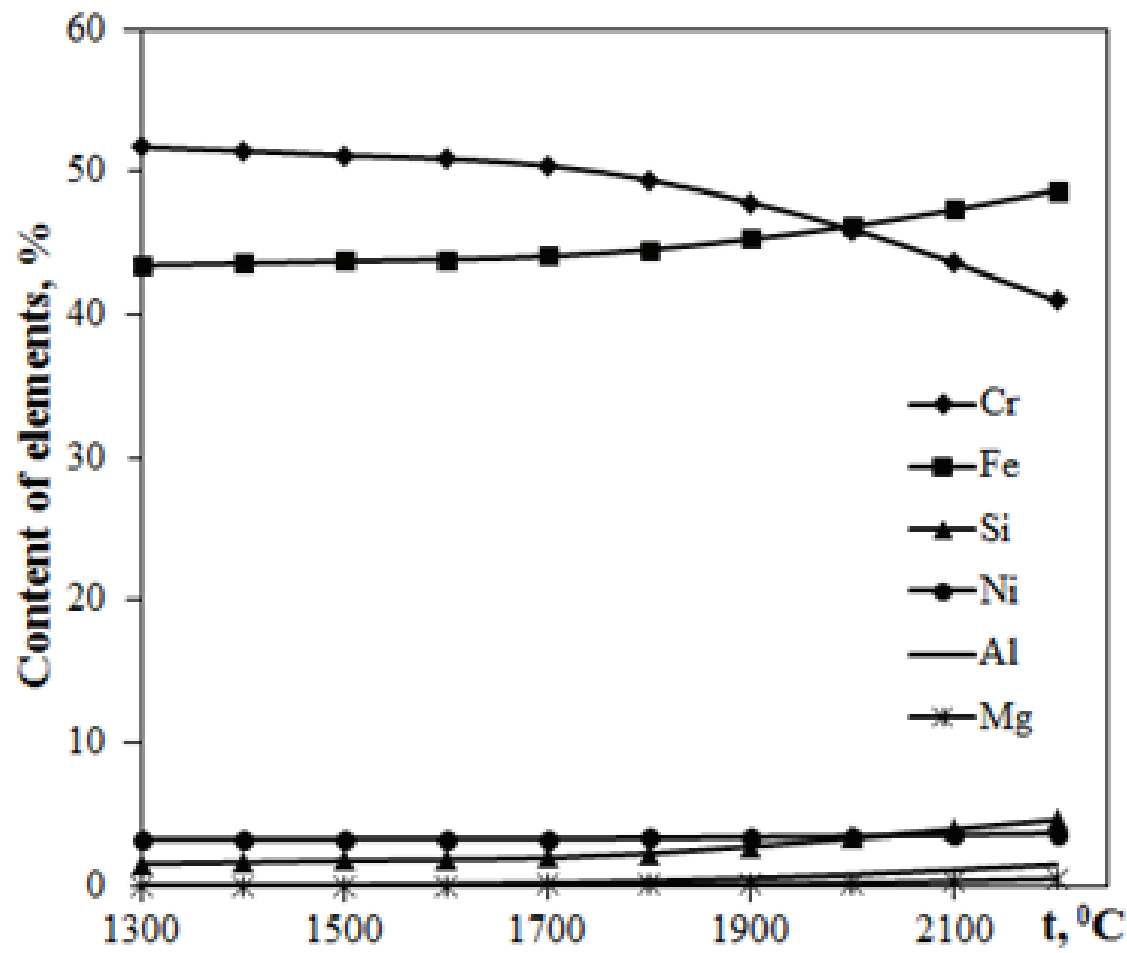

Figure 2: The change of the equilibrium composition of the metal depending on temperature $(t)$ with the consumption of reducing agent of $1,05 \mathrm{~m}_{\text {reduc.agent }}$.

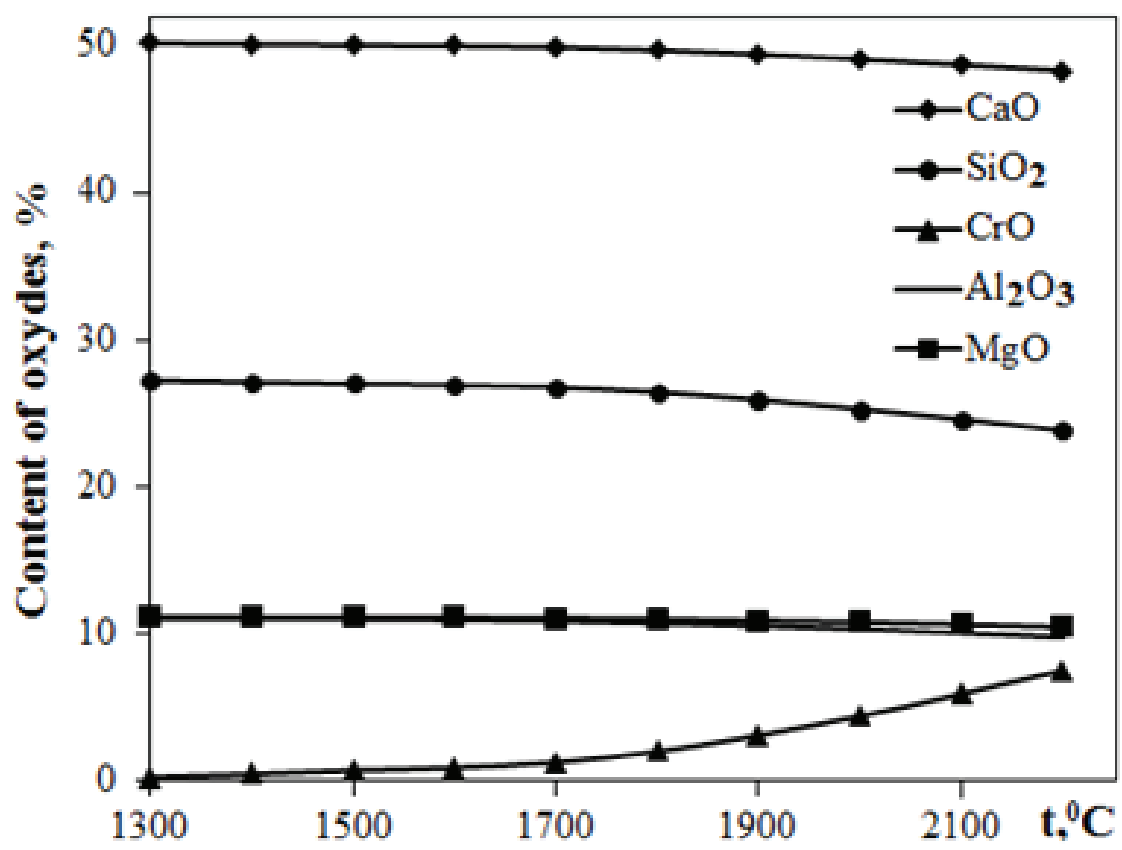

Figure 3: The change of the equilibrium composition of the slag depending on the temperature $(t)$ with the consumption of reducing agent of $1,05 \mathrm{~m}_{\text {reduc.agent }}$. 


\section{Conclusions}

1. The method of thermodynamic modeling has been used to estimate the effect of temperature on the interfacial distribution of chromium during the reduction of elements from a chrome-containing ore-lime melt by silicon of silicon ferronickel in the temperature range of $1300-2200^{\circ} \mathrm{C}$.

2. It has been established that the raising of process temperature from $1300-2200^{\circ} \mathrm{C}$ contributes to reducing of the chromium reduction rate from 98,9 to $69,8 \%$. The degree of reduction of aluminum and magnesium increases from 0,2 to $8,7 \%$ and from 0,007 to $2,5 \%$, respectively. The degree of reduction of iron doesn't change over the entire temperature range and is equal to $100 \%$.

3. The chromium content in the metal phase decreases from 51,7 to $41 \%$ with the increasing of temperature from 1300 to $2200^{\circ} \mathrm{C}$, and the residual $\mathrm{CrO}$ content in the slag increases.

4. The results of thermodynamic modeling can be used for laboratory experiments and technological calculations for producing chromium and nickel-containing complex ferroalloys suitable for smelting stainless steel grades.

\section{Acknowledgements}

This work was supported by Project No. 18-5-2345-56 of the integrated program of the Ural Branch of the Russian Academy of Sciences.

\section{References}

[1] Roine A. (2002). Outokumpu HSC Chemistry for Windows. Chemical reactions and Equilibrium software with extensive thermochemical database. Pori: Outokumpu research OY.

[2] Lukas H., Suzana G. (2007). Computational Thermodynamics: The Calphad Method Cambridge University Press.

[3] Vatolin N.A., Moiseev G.K., Trusov B.G. (1994). Thermodynamic modeling in hightemperature inorganic systems. Moscow: Metallurgy.

[4] Tanklevskaya N.M., Mikhailov G.G. (2014). Thermodynamic analysis of the possibility of obtaining low-carbon ferrochrome from local ores. Computer simulation of 
physicochemical properties of glasses and melts: Collection of works XII Russian Seminar. Kurgan: Publishing house Kurgan. State Univer. pp. 42-44.

[5] Akimov E.N. (2014). Production of low carbon ferrochrome by combined aluminosilicothermic process. PhD dissertation/Master's thesis. South Ural State University.

[6] Van Ende Marie-Aline, Guo Muxing, Jones Peter Tom, Blanpain Bart, Wollants Patrick (2008). Manganese and chromium distribution between $\mathrm{CaO}-\mathrm{SiO}_{2}-\mathrm{MgO}_{\text {sat }}$. $\mathrm{CrO}_{1.5^{-}}$ MnO slags and Fe-Cr-Mn stainless steel. ISIJ International, vol. 48, no. 10, pp. 13311338.

[7] Tsikaridze Z., Janelidze I., Razmadze R., Bagdavadze J. (2011). Thermodynamic analysis of carbothermal reduction of the mixture of $\mathrm{Cr}_{2} \mathrm{O}_{3}$ and $\mathrm{MnO}$ oxides. Bulletin of the Georgian national academy of sciences, vol. 5, no. 3, pp. 77-78.

[8] Zhang Yang-ling, Liu Yang, Wei Wenjie. (2013). Carbothermal reduction process of the $\mathrm{Fe}-\mathrm{Cr}-\mathrm{O}$ system. International journal of minerals, metallurgy and materials, vol. 20, no. 10, pp. 931-940.

[9] Gutierrez-Paredes J., Romero-Serrano A., Plascencia-Barrera G., Vargas-Ramirez M., Zeifert B., Arredondo-Torres V. (2005). Chromium oxide reduction by silicon and magnesium. Steel research int., no. 11. pp. 764-768.

[10] Zhuchkov V.I., Leont ev L.I., Selivanov E.N., Zayakin O.V., Babenko A.A. (2014). Prospects for the production of stainless steel using domestic chrome and nickel ferroalloys. Current trends in the theory and practice of mining and processing of mineral and technogenic raw materials: collection of materials international scientificpractical conference. Yekaterinburg: Publishing UMT UPI.

[11] Zhuchkov V.I., Zayakin O.V., Mal'tsev Yu. B. (2001). Study of melting temperatures and density of ferroalloys containing nickel. Rasplavy, no. 1, pp. 7-9.

[12] Zayakin O.V. (2002). Development of a rational composition of nickel-containing production technology ferroalloys from poor oxidized nickel ores. PhD dissertation/Master $s$ thesis. Ekaterinburg.

[13] Salina V.A., Zayakin O.V., Zhuchkov V.I. (2017). The study of silicothermic method of producing complex nickel-, chromium-containing ferroalloys by method of thermodynamic modeling. Science and technology of Kazakhstan, no. 3-4, pp. 8590.

[14] Sychev A.V., Salina V.A., Babenko A.A., Zhuchkov V.I. (2017). Distribution of boron between oxide slag and steel. Steel in Translation, vol. 47, no. 2, pp. 105-107.

[15] Gasik M.I., Lyakishev N.P. (1999). Theory and technology of electrometallurgy of ferroalloys: textbook for universities. Moscow: Internet Engineering. 
[16] Lyakishev N.P., Gasik M.I. (2005). Physiochemistry and technology of electroferroalloys. Moscow: ELIZ.

[17] Kadarmetov Kh. N. (1972). The processes of metal formation during smelting of various grades of ferrosilicochrome. Ferroalloy production. Chelyabinsk: South Ural book publishing house. Ministry black metallurgy of the USSR, no. 1, pp. 17-26. 